\title{
Socioeconomic Factors Hindering the Participation of Women in Managing Water Resources in Kajiado County, Kenya
}

\author{
Teresia W. Gathagu, Jones F. Agwata* \& Richard M. Mulwa \\ Centre for Advanced Studies in Environmental Law and Policy, University of Nairobi, PO Box 30197-00100, \\ Nairobi
}

\begin{abstract}
The important role women play in water resources management has been recognized for a long time globally and in most societies, they are the ones primarily responsible for the management of household water supply and sanitation. In these societies, women also play the role of family care givers in terms of provision of food, nutrition, clean water and sanitation. Due to these roles, they depend directly on the availability of water resources and have therefore accumulated considerable knowledge on water in terms of location, quality and storage methods. Despite the significant roles that women play in water resources management, they face various challenges that hinder them from effectively participating in its management in various parts of the world. The purpose of this study was to examine the various socioeconomic factors inhibiting the participation of women in managing water in three Divisions of Kajiado County in Kenya. Semi structured questionnaires, focus group discussions, key informant interviews and direct observations were used to collect data. The key factors found to affect the participation of women in water resources management were cultural practices, gender inequalities, lack of formal education, poor access to water sources and lack of decision making power and land ownership rights. It is recommended that concerted efforts be made to educate the local community, improve access to water sources through construction of multipurpose water projects and gender mainstreaming in water resources management in the County.
\end{abstract}

Key words: socioeconomic factors, water resources, participation, women

\section{Introduction}

Water is one of the most important resources for man's survival and it is essential to human beings and all forms of life. It is necessary for sustainable development, poverty eradication, reproductive and maternal health, and in combating diseases. Unfortunately, one third of the world's population experiences some kind of physical or economic water scarcity (Cech, 2009). Due to increasing demand for water from different sectors such as industry, agriculture, power generation, domestic use and the environment, it is increasingly difficult for poor people to access the resource for productive, consumptive and social use.

In areas facing water scarcity, access to water resources is a serious challenge due to competition for the resource. Where there is competition, it is the poor and the vulnerable who suffer. In most societies, women are usually considered poor and vulnerable. According to UNDP (2006), water availability is linked to poverty, food security, health, gender equality and gender equity. Inadequate and unequal access to water is both a result and cause of poverty and can be termed as a denial of human rights, good health, adequate nutrition, literacy and employment. Access to adequate amounts of clean water is essential for maintaining good health, and access to water for agriculture is essential for food production. When it is scarce, competition for it will lead to the vulnerable groups being deprived. Women, children, the sick and the elderly people will suffer the most (Angula, 2010). Although the links between water and poverty may be easy to grasp, the issue of how to organize our societies and our water resources so that the poor are able to access water for consumption and production has not been given necessary attention. According to IFAD (2007), water is essential for food production and food security and an estimated 70 per cent of available freshwater resources are used for irrigation.

In most sub-Saharan Africa and Latin America there is considerable untapped potential for bringing more land under irrigation. Irrigation does contribute to poverty reduction, and its development can be made more pro-poor by securing better access to water for poor farmers especially women (FAO, 2003). When there is lack of water, it is the women who spend so many hours looking for it. Children are also affected because instead of going to school, they are forced to accompany the women in search for water. Water is a basic necessity of life and when it is scarce, the hours women spend searching for water could otherwise be used in more productive work like education and agricultural production. This could contribute towards improving the general well being of the families (Denton, 2000). Lack of access to water causes gender inequality, poverty and lack of education to women. According to WHO (1997), access to safe drinking water averages of 20 liters per 
person per day within one kilometer walking distance from the household, while basic sanitation refers simply to a sanitary means of excreta disposal.

Access to safe drinking water is also very critical to the attainment of the Millennium Development Goals. Water is essential in eradication of extreme poverty and hunger, improving maternal health, achieving universal primary education, promoting gender equality and empowerment of women, reducing child mortality. Nevertheless, despite this undisputed importance of water, securing access to safe drinking water has only fairly recently become one of the key goals of development. Due to the importance of water as a resource, it is imperative that it be managed sustainably. This calls for integrated water resources management which coordinates the development and management of water related resources while seeking to maximize social and economic welfare in an equitable manner, to sustain ecosystems and to bring together the technical, ecological, social and political spheres. An essential part of an integrated approach is the participation of all stakeholders, including local communities and women (Biswas, 2004).

In most societies, women have the primary responsibility for management of household water supply, sanitation and health. In these societies, women play the role of family care givers in providing food, proper nutrition, clean water and proper sanitation. Due to the said social roles, women on their daily activities depend directly on water resources. As a result, women have accumulated considerable knowledge about water resources, including location, quality and storage methods (GWA, 2009). Previous studies have suggested that men and women have different interests in the management and use of water resources. The two genders obtain different benefits from the resources. When there is poor sanitation, water and food scarcity, girls and women become the major victims. As such they are most committed to ensuring that water resources are sustainably managed (GWA, 2009). This attests to the fact that when people influence or control decisions that affects them, they have a greater stake in the outcomes and are committed to ensuring success. Participation of women therefore would produce more efficient and more sustainable water plans, projects and programs.

A study done in Kericho County by Were and Roy (2004) established that committee and association membership in the existing water associations is exclusive to men. It was established that the only registered female member of Chesilot water project had recently relinquished her position to her son. During group discussions it was also revealed that it is the men who had taken lead roles in initiation and implementation of the projects. On the other hand, women were responsible for preparing meals and child care and could not participate in the meetings. They were the ones to prepare meals when meetings are held in their homes. In another study conducted in the Upper Nyando River Basin by Were and Roy (2008), it was found that in one community where obstacles to organize were overcome and a successful piped water system installed, women were able to use the time saved from water collection to enhance household tea production and establish a group that has generated new income from casual labour and the production and sale of new crops. In other communities, however, it was established that men were not sensitive to how lack of access to water imposed a heavy burden on women. During the study a key informant quoted a man in a community meeting where water projects were being discussed wondering what women do when water is available at home. Out of the 50 people present, only 2 were women a clear indication that women were not participating in decision making forums. If they were, the decision of the meeting could have been different and could have most likely resolved to commence the water project. In this study, the social, economic and political factors which hindered women from participating in water resources management were not examined.

The importance of involving women in the management of water resources has been recognized at the global level. In most societies, women have the primary responsibility for management of household water supply, sanitation and health. In these societies, women play the role of family care givers in providing food, proper nutrition, clean water and proper sanitation. Due to the said social roles, women depend directly on water resources. Women have therefore accumulated considerable knowledge about water resources, including location, quality and storage methods (Agarwal, 1998). The Kenya Government together with other development agencies has made commitments to ensure enhanced participation and involvement of women in the management of water resources. Towards this end, policies and legislation have been put in place to enhance their participation. However, the implementation and effectiveness of these policies and legislation has not been clearly established especially in the traditional rural contexts of Kenya and especially in Kajiado County.

The National Vision and Strategy for Natural Resources Management in the Arid and Semi Arid Land (ASALs) acknowledges that due to their cultural and social roles, women are placed in a situation where they are likely to bear most of the burden associated with environmental degradation such as climate change, desertification, land degradation and deforestation $(\mathrm{GoK}, 2011)$. Any effort towards improving access to water and ensuring sustainable management of the resource should have full participation of all stakeholders including women. However, access to clean water remains a primary challenge in the ASALs of Kenya. Kajiado County is situated within the ASALs and the protection of water sources and management of water points is a primary responsibility of women as they are usually expected to provide water for domestic consumption as well as for 
livestock. However due to various factors, men dominate water committees and the user groups. Long distances to water points (average $10 \mathrm{~km}$ one way) and poor workmanship in the water points also expose women to constraints and hardship (GoK, 2008).

Despite the recognition of the important role played by women and the efforts that the Government has made in enhancing women's participation in water resource management, there is an existing gap between written intentions of enhancing women's participation in water resource management and the practice in Kenya and specifically in Kajiado County. It is against this background that this study was conducted to investigate how women are participating and the factors hindering their effective participation in water resources management.

\section{The Study Area and Methodology}

Kajiado County is located on the extreme southern part of the Rift Valley of Kenya. The County boarders Narok to the West, Nakuru, Kiambu and Nairobi to the North; Machakos to the East, Taita Taveta to the South East and the Republic of Tanzania to the South. The County covers an area of $21,903 \mathrm{~km}^{2}$ and is divided into seven administrative divisions namely, Ngong, Isinya, Loitoktok, Magadi, Namanga, Central Kajiado and Mashuru (GoK, 2008).

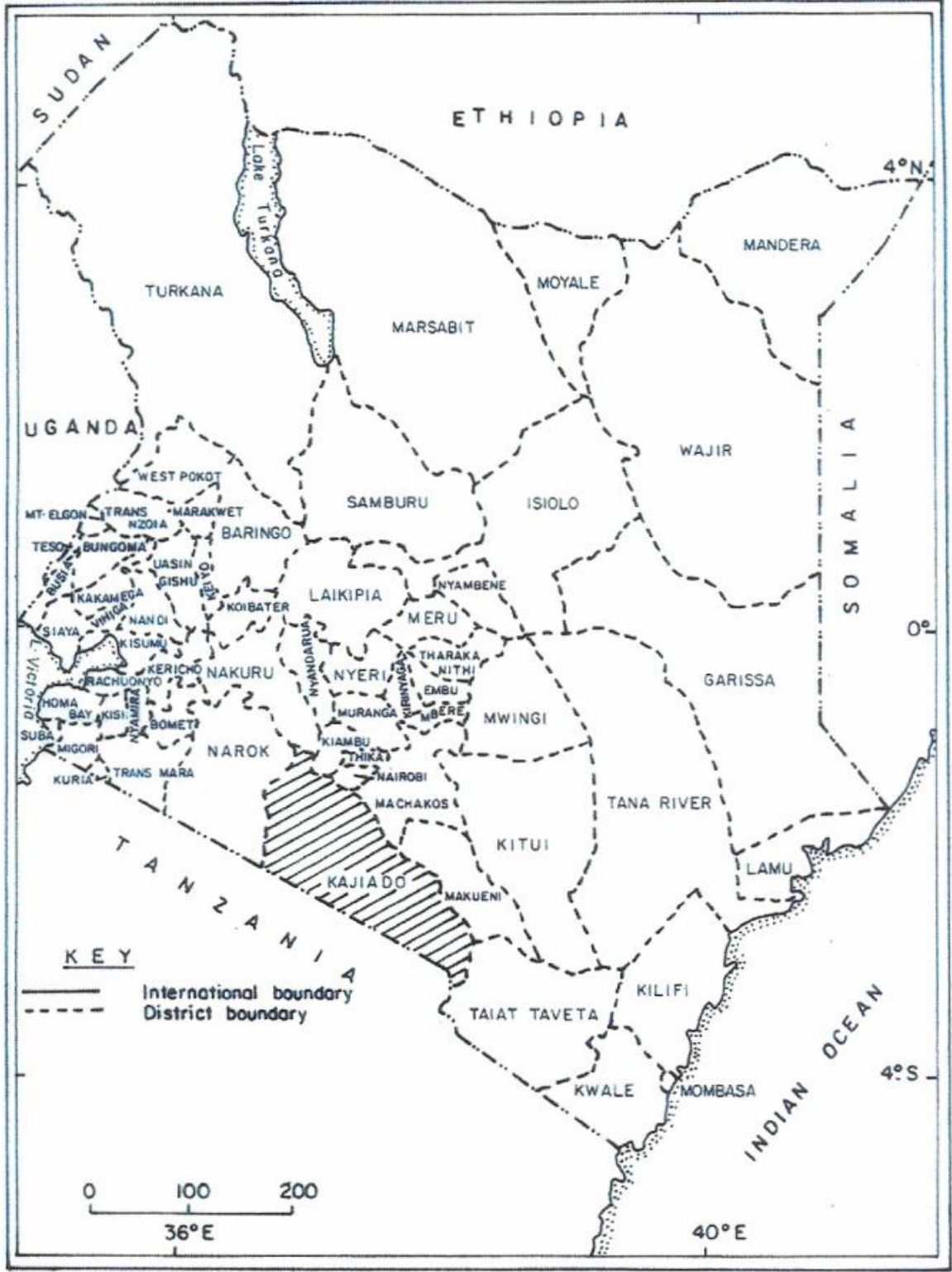

Figure 1: Map of Kenya showing the location of Kajiado County (Source: GoK, 2008)

The County has a varied climate, with a bimodal rainfall pattern with the long rains falling between March and May while the short rains fall between October and December. The rainfall is strongly influenced by altitude 
with the heaviest occurring around Ngong Hills, Chyulu Hills, Nguruman Escarpment and the slopes of Mt. Kilimanjaro. The rainfall ranges from $1250 \mathrm{~mm}$ near Mt. Kilimanjaro to less than $500 \mathrm{~mm}$ per annum at Lake Magadi. Temperatures vary in altitude to a mean maximum of about $34^{\circ} \mathrm{C}$ at Lake Magadi to a mean minimum of $22{ }^{\circ} \mathrm{C}$ at Loitoktok and Ngong (GoK, 2008)

The vegetation of Kajiado County is determined by altitude, soil type, and extent of human occupation and utilization of the land. The main vegetation types consist of grassland, scrub and semi desert bush land. The vegetation cover throughout the County varies seasonally with rainfall and grazing intensity. Semi-nomadic pastoralism has been the traditional Maasai mode of life, practicing on land that was communally owned. However, this lifestyle has undergone changes due to ongoing land adjudication and sub-division of group ranches leading to individual land tenure system. This has increased the rate of land sales thus opening to immigration especially in the relatively high agricultural potential areas of the district to farming communities from other parts of the country. These areas include Ngong, Nguruman and Magadi divisions and foot slopes of Namanga hills (GoK, 2008).

\section{The water situation in the County}

Nearly $95 \%$ of its streams in the County are seasonal, while the rest are perennial. The perennial streams are found at the foot slopes of Mt. Kilimanjaro, Ngong Hills, Ngurumani Escarpment and Namanga Hills. Other sources of water include boreholes, dams, pans, wells, springs, roof and rock catchments. The average distance to nearest potable water point is $15 \mathrm{~km}$ to $10 \mathrm{~km}$ during the dry season and 10 to $5 \mathrm{~km}$ in the wet season. The water sources in the county are distributed as shown in the following table (GoK 2008). The distribution of water resources in the County is shown in Table 1.

Table 1: Distribution of Water Resources in Kajiado County

\begin{tabular}{|l|l|}
\hline Water source & Number \\
\hline Permanent rivers & 3 \\
\hline Shallow wells & 1,000 \\
\hline Unprotected springs & 22 \\
\hline Protected springs & None \\
\hline Water pans & 400 \\
\hline Water dams & 145 \\
\hline Boreholes GOK/Community & 436 \\
\hline Boreholes Private & 300 \\
\hline Boreholes Institutional & 264 \\
\hline
\end{tabular}

\section{Source: GoK, 2008}

Kajiado is an arid and semi-arid land County with livestock keeping being the predominant economic activity. Most of the land (92\%) is non-arable, while only $8 \%$ is said to support subsistence farming. Being an ASAL area, only $10,500 \mathrm{Ha}$ is under food crops. Horticulture growing is being intensified through small scale irrigation schemes in Magadi Division and individual farmers using boreholes (GoK, 2008).

\section{Study Population and Unit of Analysis}

The study was done in three out of the seven divisions of the County. These are Central Kajiado, Namanga and Mashuru. The three divisions were randomly picked with one third of the locations in each of the sampled divisions were then randomly picked as shown in Table 2 . The number of household sampled per every location was computed from the total number of household in the location. A total of 196 respondents were interviewed in the study. According to the Maasai culture, women are not supposed to give information or speak to strangers. Women also do not speak in the presence of men. To overcome this obstacle, the local administration stepped in and convinced the women to give information to the research team. It also became necessary to hold focus group discussions exclusively for women so as to enable them express themselves freely. 
Table 2: Total Population in the selected Divisions of Kajiado County

\begin{tabular}{|l|l|c|c|c|c|}
\hline Division & Location & $\begin{array}{c}\text { Population per } \\
\text { Location }\end{array}$ & Female & Male & No of households \\
\hline \multirow{4}{*}{ Namanga } & Bissil & 15355 & 7933 & 7422 & 3567 \\
\cline { 2 - 6 } & Namanga & 18515 & 9138 & 9377 & 3508 \\
\hline \multirow{5}{*}{ Central } & Elangata WUAS & 4648 & 2256 & 2392 & 941 \\
\cline { 2 - 6 } & Loodokilani & 5173 & 2528 & 2645 & 1036 \\
\cline { 2 - 6 } & Sajiloni & 7484 & 3825 & 3659 & 1529 \\
\cline { 2 - 6 } & Township & 14956 & 7372 & 7584 & 4256 \\
\hline \multirow{4}{*}{ Mashuru } & Ilmunkush & 8068 & 3916 & 4152 & 1639 \\
\cline { 2 - 6 } & Nkama & 11449 & 5795 & 5654 & 2496 \\
\cline { 2 - 6 } & Poka & 5567 & 2797 & 2770 & 1184 \\
\cline { 2 - 6 } & Total & $\mathbf{9 1 2 1 5}$ & $\mathbf{4 5 5 6 0}$ & $\mathbf{4 5 6 5 5}$ & $\mathbf{2 0 1 5 6}$ \\
\hline
\end{tabular}

Source: Kajiado District Statistics Office, 2008

A semi-structured questionnaire with open ended and closed questions was administered to both men and women respondents. This covered a wide range of social and economic aspects. This technique was used to explore the individual's opinions on issues related to management of water resources. Open-ended questions gave the informants an opportunity to give their views freely. This way the informants' subjective and personal views as well as observations and perceptions concerning the role of women in the management of water resources were captured. Opportunities for substantiation and probing were provided through requesting the respondents to clarify their responses by explaining or discussing further.

Focus group discussions were conducted with a total of six focus groups, two being randomly picked from each of the sampled divisions. Each group consisted of six to eight members. The participants were women who were considered to have participated in various committees of water resources management and were holding key positions of leadership in such committees and who were ready to share their ideas and knowledge on water resources and its management. Women who were taking care of their households by providing water and food were also included in the focus group discussions. The selected women were usually involved in making decisions regarding the acquisition and use of water and also due to their familiarity and better understanding, especially on their role in water resources management.

Key informant interviews were conducted to collect data from those who had more information and experience regarding water resources management and in particular the participation of women. A total of eleven people were interviewed. These were mainly government officials including the County Water Officer, County Development Officers, Chiefs and Sub Chiefs, officials from three Non-Governmental Organizations namely, World Vision, German Agro Action (GAA) and African Medical and Research Foundation (AMREF). Other key informants were from Community and Faith based Organizations. Direct observations were used to provide useful information which respondents could not have disclosed. It served as a link between knowledge and practice. Direct observations were used to document the day-to-day activities of the people and the participants involved. This provided additional information on water quality, roles of women, social status, standards of living, their health and that of their children.

\section{Study findings}

Several key challenges affecting women's participation in water resources management in Kajiado County were identified. These challenges affect women in different ways at different levels.

\section{Culture}

In this County, life revolves around livestock and water projects are meant to provide water for livestock. The study established that at the boreholes there is a single water point, where water is drawn from a single trough. Since men own the livestock, they control the water point and ensure that the cattle are given priority to drink water. Women have to wait and are only allowed to draw water for domestic use, from the same trough, after the cattle are satisfied. It was confirmed that this has caused conflicts between men and women and it also compromises on the water quality with adverse effects on health of the entire livelihoods. The culture also dictates that women are subordinate to men; they are not expected to speak in public or in the 
presence of men let alone to opposing or arguing with them. This was found to be one reason why women have not been effectively participating in water resources management.

\section{Gender inequality}

Findings of this study confirmed that the Masaai exhibit gender inequality in the form of patriarchy .The pattern has influenced customary marriages, inheritance of property and control over resources. Masaai women experience subordinate social status and they are responsible for most of the household chores with no decision making power within the household and the community. Management and control over resources such as livestock and income from all sources is vested in the man. Women are thus regarded as dependants and therefore required to follow decisions and directions by the men and this makes them socially vulnerable. Subsequently, women have unequal access to information, water resources and are underrepresented in decision making. This denies them opportunities to negotiate upon their concerns at policy level thus their practical needs are rarely addressed.

\section{Lack of formal education}

The study revealed that the incidence of gender discrimination in education is still high. In many occasions, eight out of 10 girls had failed at times to go to school and had to assist their mothers in collecting water. It was also revealed that young women are usually circumcised at the tender age of 10 to 15 years and married off to elderly men -men. Girls are usually considered as assets by the Maasai community who after being married off earn them dowry in terms of livestock. This denies the girl child an opportunity to acquire education and technical skills. Most women therefore lack formal education, especially in rural areas where there is low level of awareness on the importance of education by the community. As a result, women lack capacity to participate in water resources management.

\section{Poor access to water sources}

The study found that women walked for between 10 and $15 \mathrm{~km}$ to the water sources. If women have to spend so much time collecting water, their other obligations are not fulfilled and this created conflicts with the husbands at home. Carrying water for long distance and sometimes up a steep terrain also led to health risks such as frequent headaches and backaches, malformed spine, obstructed birth and high mother and baby mortality rates. To avoid these problems, women confirmed that they are sometimes tempted to collect water from contaminated sources because it is easy to access it. This also has wide implications on children's school. The respondents revealed that it is customary for girls to be kept home from school to help their mothers in fetching water. Lack of access to clean water is blamed as one of the major causes of school drop out by girls in the County.

According to the Kajiado District Development Plan (GoK, 2008), Kajiado County experiences serious water scarcity and people travel an average of 15 kilometers from the homesteads in search for water. On water and sanitation, the Development Plan states "the provision of water for household is usually the duty of women". This task exploits their energy and time. Their daily and direct contact with water makes them particularly susceptible to water related diseases which further endanger their health". This is evidence that access to safe drinking water in Kajiado County is far from being realized. The study further revealed that poor access to clean water has been a cause for conflicts where women have been adversely affected. For example, collecting water $15 \mathrm{~km}$ away can cause conflict at home because women spend so much of their time fetching water; hence their other domestic obligations cannot be fulfilled. This is likely to cause disagreements with their spouses and result to domestic violence.

A key informant from African Medical Research Foundation (AMREF) a Non-Governmental organization informed the researcher that in the Maasai community, water is meant for livestock. Since the Maasai women do not own livestock, they cannot control or manage the water. Furthermore, there is only one watering point at the borehole where livestock will drink water first until satisfied while women are waiting. They will then fetch water for domestic use from the same point. This key informant narrated an incident where a woman was assaulted by a man (not her husband) in public at a watering point because she went to fetch water when the cattle were still drinking. The case was, however, reported to the police and the man was charged with a criminal offence. In order to prevent such disputes, the NGOs sponsoring boreholes are now creating two separate water points, one for men and the other for women, to address the needs of women.

\section{Lack of decision making power}

This study also established from focus group discussions and key informant interviews that in most areas, women were still underrated and thus not deemed fit to be in leadership position. Nonetheless, due to the constitutional requirement for equality, men were left with no option but to allow women to be part of the managing team. However, it was found that even after women are included in water management, they still fear 
speaking in the presence of men because of culture. One respondent was quoted saying "if a man has said something, no woman can say otherwise as this may cause a lot of conflict and can make her to be beaten".

Men are also revered in the community because they own all the resources, are the family heads and decision makers. Women are not allowed to speak in public as per the culture and are not expected to argue with or oppose men. Women, therefore, fear in demanding their rightful position in elective posts to avoid discrimination both at home and in public. Even among people residing in urban centers such as Kajiado town in Township location and Namanga town where people were more informed and educated, the culture factor was still an issue to them. A key informant revealed that during elections, people cannot elect a woman.

Women in Kajiado County still face lot of barriers to participate in community development activities including water projects. These barriers include refusal by husbands to attend meetings that addressed issue of safe water, discrimination, subordinate roles, weak leadership, lack of mobilization, lack of time and failure to see the benefits of their participation. Their participation in water projects is largely centered on the provision of their labour for unskilled work, often adding to their already heavy workload. This is an indication that although policymakers had undertaken efforts to encourage women's participation in Water resources management, women did not participate effectively due to lack of confidence in standing up for their rights. Illiteracy and social norms prevented women from taking up any public role. Even where women have been given a responsibility in the water committees, they have often been token representatives with a passive role without effective participation.

\section{Lack of land ownership rights}

Property ownership was another factor that was raised as it played a big role in leadership in this community; therefore since women are not allowed to own property, they are subsequently kept away from various leadership positions. During focus group discussions, it was established that most people still respected and adhered to cultural beliefs that women should not own land, because they were seen as outsiders or people who would be married and join other families. However, the educated women especially those in urban centers had bought their own land. A scrutiny about situations in a widow and widower case revealed that in areas where the culture was practiced heavily, after the husband's death, the land was transferred to the sons. Nevertheless, some respondents said that sometimes, though rare, in a situation of a husband's death land was transferred to the widow. Most women who owned land were single and were only found in urban centers.

Land ownership is a precondition for access to water in many countries. Women's failure to own land has negatively affected their access to water and hence their participation in water resources management. The participants said that this made them to be underrated, while others added that they were unable to make a meaningful contribution as their opinions were ignored by men who claimed that their decisions were baseless and could not be affected by someone who did not own anything.

A significant number of the boreholes in Kajiado are sponsored by Non-Governmental Organizations such as African Medical Research Foundation (AMREF), German Agro Action (GAA) and World Vision. A key informant from AMREF told us that during elections for borehole management committees, men cannot elect a woman because water is for livestock and women do not own livestock. Further, a woman cannot be elected treasurer because money belongs to the men. However, the sponsors always insist on one third of the positions being reserved for women hence women have found their way into the committees. The informant blamed the Maasai culture and said that even after the women have been put in the committees, they rarely attended the meetings and when they attend, they sit at the back and do not participate. According to this informant, women are not supposed to speak in public or even oppose men.

On how to improve the participation of the women in the management of water resources, the respondents were positive that there has been an increase in the number of women in water resources management. This was attributed to an increase in women's education, income levels, and awareness of women's rights among others. Due to the constitutional requirement and government policies requiring one third of the positions reserved for women various Non-governmental Organizations (NGOs) and the government funded projects have put in place appropriate measures to ensure women are involved in every level of management. The strategies and approaches used to enhance women's participation in water resources management should also include women being appointed in senior positions in the water management committees. During focus group discussions and key informant interviews, respondents indicated that the trend in the sampled locations has been that women are usually appointed as treasurers and secretaries. No woman has ever been appointed as chairman. Nevertheless, it was unanimously confirmed that if it were not for the laws and policies, masaai-Masaai men would never elect a woman to a leadership or management position. Unfortunately, it was also disclosed that even where women have been appointed into the water committees, they are just but numbers for compliance purpose and they do not participate effectively.

Another suggested strategy included initiation of more community based water resource management programs targeting women, gender equality promotion and affirmative action as measures for enhancing 
women's participation. It was strongly felt that Government's intervention through policies addressing lack of education, poor access to water and the retrogressive culture would enhance women's participation. Seminars and training targeting both men and women to create public awareness were also recommended as measures to encourage equality in decision-making within the community.

\section{Conclusion and Recommendations}

Despite the recognition of the important role played by women and the efforts that the Government has made in enhancing women's participation in water resource management, there still exists various challenges that hinder effective participation in water resource management in Kajiado County. These challenges include cultural practices, gender inequalities, lack of formal education, poor access to water sources, lack of decision making power and land ownership rights. Laws, institutions and policies on water management are also not adequate to support and enhance women's participation in the management of water resources. On the basis of the findings, the following measures are recommended.

\section{a) Capacity building}

Targeting women for training and capacity building is critical to the sustainability of water and sanitation initiatives particularly in technical and managerial roles. This will empower them to participate in the decisionmaking process, making their needs to be addressed at the policy level. The empowerment of women as water managers should also be done at the grassroots level. Training programmes targeting women are essential so that the women are equipped with skills to manage water programmes and projects. There is, therefore, need for a special approach to girls education especially in technical aspects. As revealed in the literature review, in South Africa, Uganda and Lesotho, women at the local level have been trained to locate water sources in the village, to decide on the location of facilities and to repair pumps. Affirmative action policies such as 'women in water' awards and a bursary for young women to take up careers in the water sector in South Africa have proved to be successful means of empowering women.

\section{b) Education and public awareness}

Although basic education is now free and compulsory, this government policy has not been fully implemented in Kajiado County. There is need to sensitize parents to take advantage of the government policy and allow their children especially girls to attend school. The government should also ensure strict enforcement of the free and compulsory education policy for all the children in Kajiado County. Most projects are run by agencies and within communities where little gender sensitization has taken place and where awareness and understanding of gender inequality is low. It is important to sensitize all the stakeholders, men and women on the importance of involving women throughout the whole project process from planning, implementation, monitoring and evaluation. Extensive and intensive social mobilization should precede project implementation so as to create a sense of awareness and ownership, and to bring about attitudinal change. Successful mobilization requires a minimum of six months prior to implementation. This is the only way to ensure that the policies advocating for women's participation in decision making are understood and accepted at the community level.

\section{c) Improved access to water}

Access to safe drinking water is a basic human right and essential for achieving gender equality for sustainable development and poverty alleviation. Providing physically accessible clean water is essential for enabling women and girls to devote more time to the pursuit of education, income generation and even the construction and management of water and sanitation facilities. The government together with other development partners should provide water at reasonable distance, quality and quantity. This should be done not only to address health and sanitation issues, but also to reduce the everyday drudgery or women by providing them with more time for self-improvement and participation in water resources management. It is also a key to the attainment of the millennium development goals and Vision 2030.

\section{d) Establishment of multi-purpose water projects}

Not addressing the multiple uses of water has been found to be one of the causes of the low participation of women in the water resources management. Water in Kajiado is essentially meant for livestock and only one water point is provided. The projects should be designed in consultation with both men and women so that different water points are made to provide water for domestic use, for livestock and even irrigation. This would ensure that women do not spend so much time collecting water and that the water is not contaminated. The projects should also be designed to provide water for agriculture to enable women grow food crops for feeding their families and also for income generation. This will lead to the empowerment of women and enhance their 
capacity to participate in water resources management. The study revealed that, at present water project are basically aimed at providing water for livestock.

\section{e) Gender mainstreaming in water resources management}

Mainstreaming gender is a process of assessing implications for women and men in any planned action, including legislation, policies, or programmes, in any area and at all levels. It is a strategy to include women's concerns and experiences in design, implementation, monitoring and evaluation of policies and programs in all social economic levels so that women and men benefit equally and inequality is gradually reduced. The ultimate goal of gender mainstreaming is to achieve gender equity- equal access to participation in the decision making process, resources and benefits, ultimately leading to women's empowerment. There is need to institutionalize gender mainstreaming through policy, legislation and financing. The government should provide steady and secure resources to support the necessary structures and programs.

Among the key tools of gender mainstreaming is gender analysis, which seeks to determine the differences between men and women in terms of rights, responsibilities, access to resources, power and the like in a given situation. It is therefore important to carry out a gender analysis in Kajiado County to gain a clear understanding of the actual situation of both men and women. A thorough knowledge of social realities and gender power dynamics prior to projects design, planning and implementation is required for all the water projects.

\section{f) Strict enforcement of the Constitution}

Stored wealth in the form of livestock and land is in the hands of men. Many women do not control cash income and therefore cannot make financial decisions. Women tend to be left out of decision making processes mainly due to their social status as dictated by the Masaai culture. Men are the heads of households, while woman are considered as assets to the men. The community needs to be sensitized on the constitutional provisions outlawing all forms of discrimination based on sex such as in the ownership of land and in education. Both men and women need to be informed on the one third gender legal requirement which provides that no single gender should have more than two thirds representation in any elective and appointive positions. This will eventually cause a change of attitude.

\section{g) Gender policy in water resources management}

It is imperative to have a gender policy in Water Resources Management to guide the government, nongovernmental and donor organizations involved in water provision and management in addressing gender issues in their water programs, through their policies, procedures and personnel. The gender analysis of these implementing agencies should include their organizational structure and culture; their policy formulating mechanisms; the organizations objectives and strategies; the personnel policies and human resource development; the provision of gender training; and the role of change agents in the organization. Gender balanced policies in water resources management should acknowledge the intention of improving the lives of women and enhancing their participation. Policy and Legal positions should aim to break the marginalized position of women in management of water resources.

\section{Acknowledgements}

The findings in this study were part of work done by the first author during her Masters work at the University of Nairobi. The various people who provided data and other logistical support are appreciated. The women in Kajiado County who presented themselves to provide insights on the challenges they face in managing water in the County are greatly appreciated.

\section{References}

[1]. Agarwal, B. 1998. The Gender and Environment Debate, in Keil, R. et al (ed), Political ecology: global and local. Routledge, London

[2]. Angula, M. 2010. Gender and Climate Change: Namibia Case Study. http/www/fanrpan.org/documents/doo923 accessed on $20^{\text {th }}$ April, 2011.

[3]. Biswas, A. K. 2004. Integrated Water Resources Management: A Re-assessment. Water International, Vol. 29, No.2, 248-256.

[4]. Cech, T. V. 2009. Principles of Water Resources: History, Development, Management, and Policy. Wiley Publishers, New York. P 138

[5]. Denton, T. 2000. Climate Change; Learning from Gender Analysis and Women's Experiences of Organizing for Sustainable Development. Gender and development Journal Vol. 2:10-20.

[6]. GoK, 2008. Kajiado District Development Plan (2008-2012), Government Printer, Nairobi

[7]. GoK, 2011. National Vision and Strategy for Natural Resources Management (2005-2015), Government Printer, Nairobi

[8]. GoK, 2011. The National Strategy for the Development of the Arid and Semi-Arid Lands, Government Printer, Nairobi 
[9]. FAO 2003. Agriculture, Food and Water Development; a contribution to the World Water Development Reports. http://www.unep.org (accessed online on $5^{\text {th }}$ May 2011)

[10]. GWA, 2009. Study done in Kenya by a Rapid Assessment an attempt to establish the extent to which gender mainstreaming has been advanced within the framework of reforms driven by the country national Policy on Water Resources Management

[11]. Roy, J. and Were, E. 2004. Water, Women and Local Social Organization in Upper Nyando River Basin. Collective Action and Property Rights Working Paper No. 51. www.worldagrofrorestry.org

[12]. Roy, J. and Were, E. 2008. Local Organization and Gender in Water Management: A Case Study for Kenya Highlands. Journal of International Development Vol. 20: 69-81

[13]. Rogers, H. 2003. Role of Women in Water Resources Management: Strengthening and Broadening Participation.

[14]. UNDP 2006. Mainstreaming Gender in Water resources Management: A practical journey to sustainability. http://www.unep.org (accessed on $5^{\text {th }}$ Ma y, 2011)

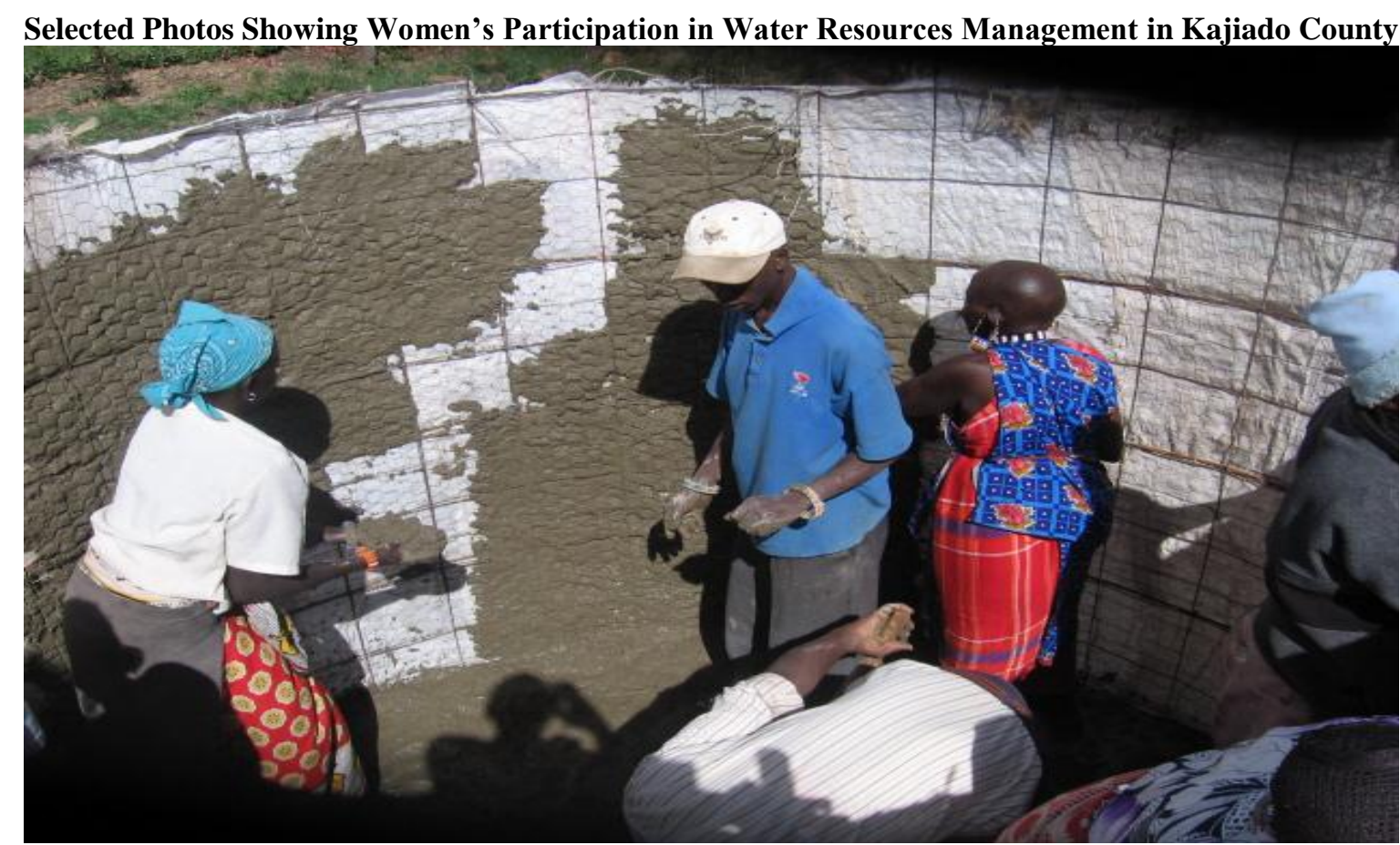

Maasai Women Constructing a Water Tank

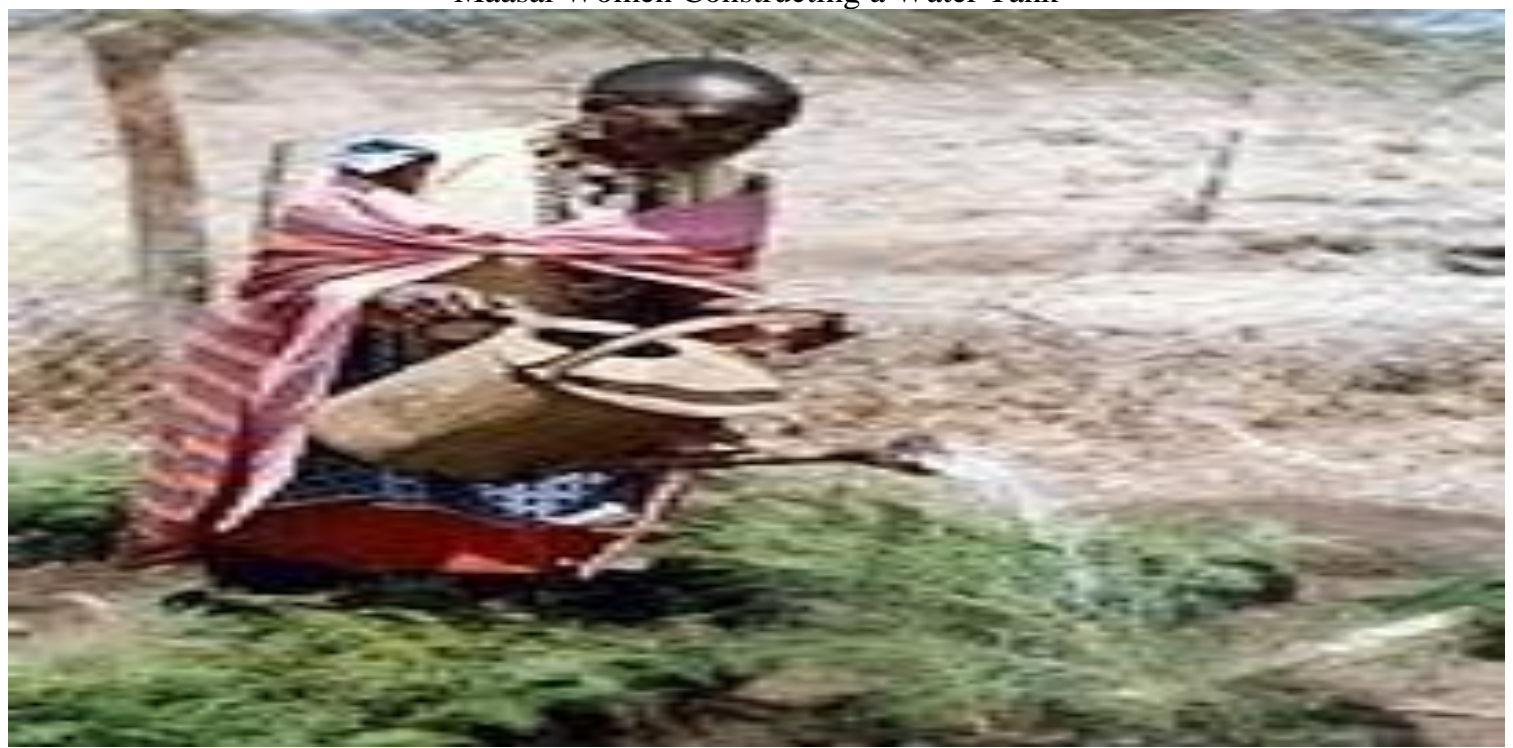

A Maasai woman using stored rainwater to water tree seedlings 


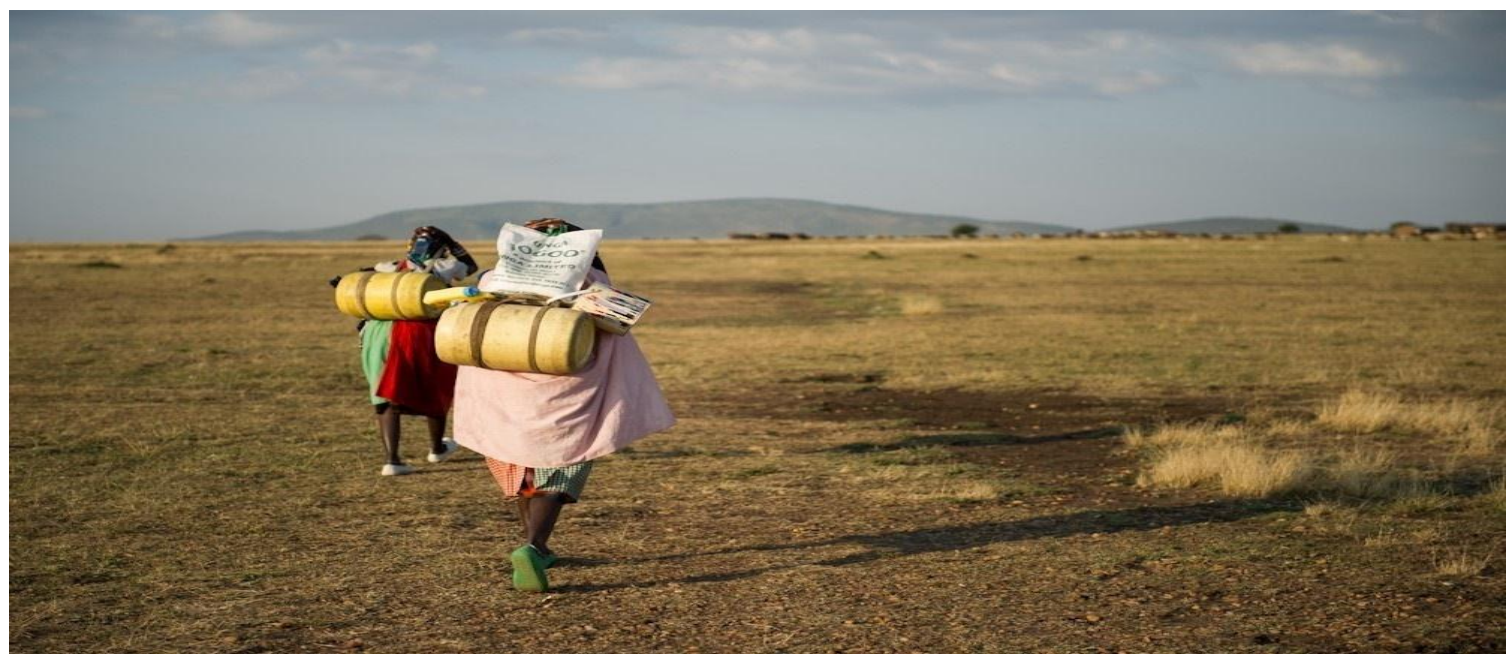

Young Maasai girls carrying water on their backs going home

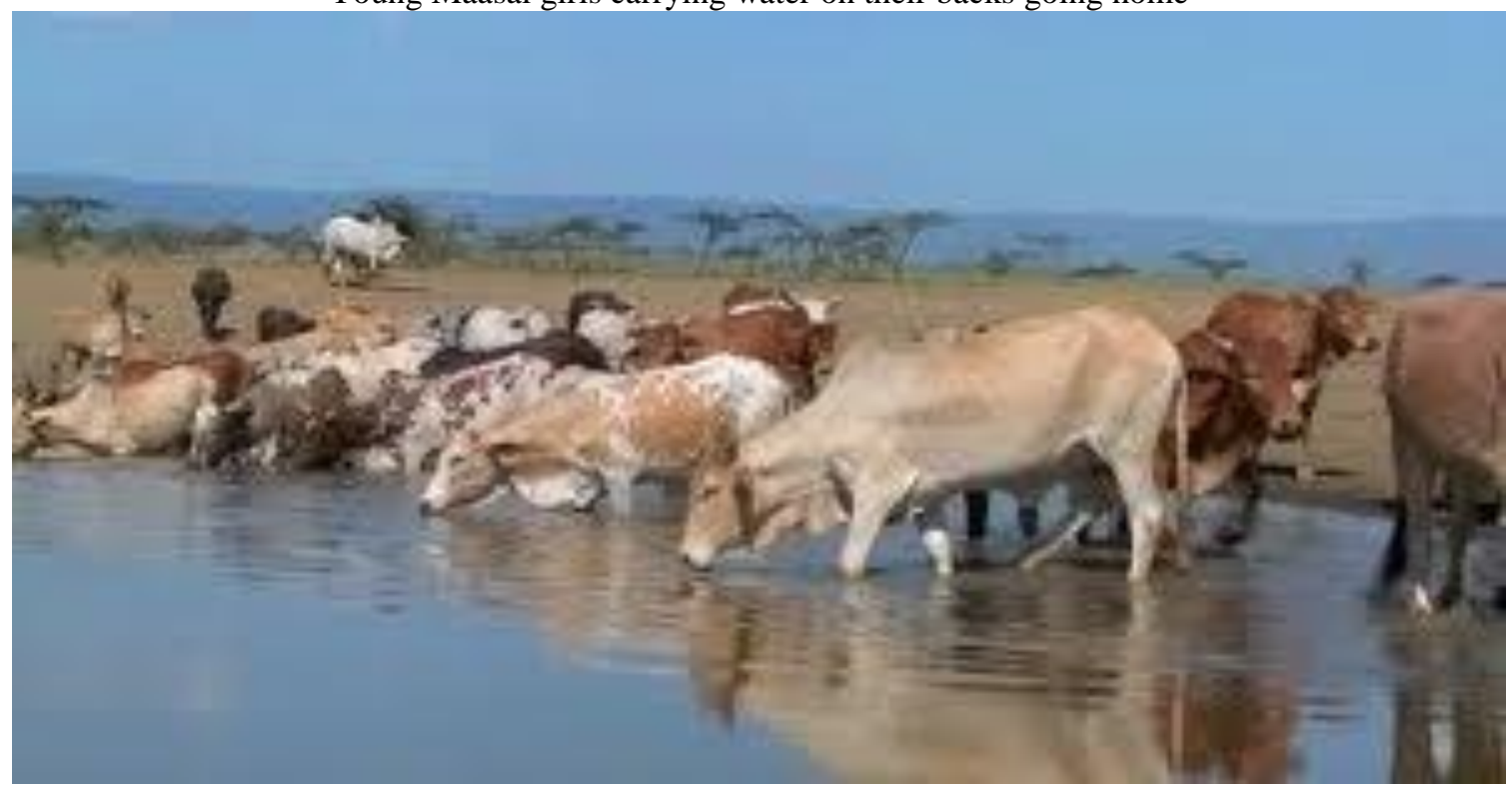

Maasai community animals drinking water from a water dam 